\title{
Differential expression of FUT1 and FUT2 in Large White, Meishan, and Sutai porcine breeds
}

\author{
R.W. Xia', W.Y. Qin ${ }^{1}$, L.N. Gan', J. Wang', S.L. Wu ${ }^{1,2}$ and W.B. Bao ${ }^{1,2}$ \\ ${ }^{1}$ Key Laboratory for Animal Genetics, Breeding, \\ Reproduction and Molecular Design of Jiangsu Province, \\ College of Animal Science and Technology, Yangzhou University, Jiangsu, \\ Yangzhou, China \\ 2 Jiangsu Engineering Research Center for the Reproduction and Healthy Breeding \\ of Boar, Jiangsu, Yangzhou, China \\ Corresponding authors: S.L. Wu / W.B. Bao \\ E-mail: slwu@yzu.edu.cn / wbbao@yzu.edu.cn \\ Genet. Mol. Res. 15 (1): gmr.15017613 \\ Received September 10, 2015 \\ Accepted December 4, 2015 \\ Published March 4, 2016 \\ DOI http://dx.doi.org/10.4238/gmr.15017613
}

ABSTRACT. To assess the relationship between the expression of $\alpha(1,2)$-fucosyltransferase (FUT1 and FUT2) genes and resistance to Escherichia coli F18 in weaned pigs, FUT1 and FUT2 expression levels in Large White, Meishan, and Sutai pigs (with resistance to E. coli F18) were determined using real-time PCR. The results revealed that FUT1 and FUT2 expression levels were higher in the liver, lungs, kidneys, stomach, duodenum, and jejunum than in the muscle and heart. Medium FUT2 expression levels were detected in the spleen, thymus, and lymph nodes. Intestinal FUT1 expression levels were higher in Sutai pigs than in Large White and Meishan pigs $(P<0.05)$. However, intestinal FUT2 expression levels were lower in Sutai pigs than in Large White and Meishan pigs $(P$ $<0.05)$. FUT1 and FUT2 expression levels did not differ between Large White and Meishan pigs $(P>0.05)$. The results revealed that high FUT1 expression levels and low FUT2 expression levels in the intestines of Sutai 
pigs affected FUT1 and FUT2 enzymes, the synthesis of type $2 \mathrm{H}$ and type $1 \mathrm{H}$ antigens, and E. coli F18 adhesion. Moreover, low FUT2 expression levels conferred resistance to E. coli F18.

Key words: Pig; FUT1; FUT2; mRNA expression

\section{INTRODUCTION}

Porcine post-weaning diarrhea (PWD) is a common disease that contributes to significant financial losses in the swine industry. Escherichia coli causing PWD and E. coli F18 is the most predominant and pathogenic bacteria in pigs (Van den Broeck et al., 2000; Boldin, 2008). Studies showed that the pathogenicity of $E$. coli F18 was dependent on the presence of specific receptors expressed on the small intestinal surface of piglets (Bertin and Duchet-Suchaux, 1991). The $\alpha 1$-fucosyltransferase gene (FUT1) plays a major role in the synthesis of the E. coli F18 receptor (Vögeli et al., 1997). Meijerink et al. $(1997,2000)$ reported that a mutation in the M307 locus of FUT1 conferred resistance to E. coli F18 infections. However, genotypes at this locus have highly skewed distributions among Chinese porcine breeds, so the gene is not suitable for the breeding of disease resistance (Yan et al., 2003; Bao et al., 2008).

The participation of the FUT1 enzyme in the regulation of the ABH blood group antigen has been assessed by thin layer chromatography, negative ion mass spectrum, and proton magnetic resonance. Studies showed that the $E$. coli $\mathrm{F} 18$ receptor determinant is a type $1 \mathrm{H}$ antigen of the $\mathrm{ABH}$ blood group (Coddens et al., 2009). The $\mathrm{ABH}$ blood group antigen is a glycosphingolipid on the plasmalemma of red blood cells, and the $\mathrm{ABH}$ blood group is determined by the types of sugars present in the glycosphingolipid. The precursor of the $\mathrm{ABH}$ blood group antigen is the $\mathrm{H}$ antigen. Moreover, the $\mathrm{H}$ enzyme is $\alpha(1,2)$-fucosyltransferase, which is coded by FUT1 and FUT2, and this enzyme catalyzes the synthesis of the $\mathrm{H}$ antigen by connecting fucose with the $\mathrm{H}$ antigen precursor. Therefore, FUT1 and FUT2 play important roles in conferring resistance to E. coli F18 in Sutai pigs (Duroc x Meishan; Bao et al., 2012).

In this study, 35-day-old Large White (foreign porcine breed), Meishan (domestic porcine breed), and Sutai pigs (with resistance to E. coli F18) were used. The expression profiles of FUT1 and FUT2 in 11 tissues of the porcine breeds were determined using real-time PCR. The correlation between FUT1 and FUT2 expression levels and resistance against E. coli F18 in piglets was calculated.

\section{MATERIAL AND METHODS}

\section{Animals and sample collection}

Four E. coli F18-resistant Sutai piglets (Sutai Pig Breeding Center, Suzhou, Jiangsu) were selected based on birth weight, weaning weight, shape, and coat color similarities (Wu et al., 2007). Four Large White and four Meishan pigs (35 days old) from Kang Le Farming Co., Ltd. (Changzhou) and Meishan Pig Conservation Breeding Co. (Kunshan), respectively, were selected and slaughtered. Tissue samples (heart, liver, spleen, lung, kidney, stomach, muscle, thymus, lymph nodes, duodenum, and jejunum) were collected, frozen in liquid nitrogen, and stored at $-70^{\circ} \mathrm{C}$.

\section{Design and synthesis of real-time PCR primers}

Real-time PCR primers were designed using the Primer-BLAST software based on the 
published porcine FUT1 and FUT2 sequences in GenBank (Table 1), and glyceraldehyde-3-phosphate dehydrogenase (GAPDH), transferrin-binding protein 1 (TBP1), and beta-actin (ACTB) genes were used as references. Primers were synthesized by Shanghai Invitrogen Biotechnology Co., Ltd.

Table 1. Real-time PCR primers and their sequences.

\begin{tabular}{|c|c|c|c|}
\hline Gene & Accession No. & Primer sequences $\left(5^{\prime} \rightarrow 3^{\prime}\right)$ & Length (bp) \\
\hline \multirow[t]{2}{*}{ FUT1 } & \multirow[t]{2}{*}{ U70883 } & F: TTTTAAGCCCCCAAACTGCC & \multirow[t]{2}{*}{126} \\
\hline & & R: TAAATCGACCCCATCAGCCTC & \\
\hline \multirow[t]{2}{*}{ FUT2 } & \multirow[t]{2}{*}{ U70881.2 } & F: AATCCCTGACCTCACTCCGTG & \multirow[t]{2}{*}{123} \\
\hline & & R: CGGAACTACAACTGCTGGCC & \\
\hline \multirow[t]{2}{*}{ GAPDH } & \multirow[t]{2}{*}{ AF017079.1 } & F: ACATCATCCCTGCTTCTACTGG & \multirow[t]{2}{*}{187} \\
\hline & & R: CTCGGACGCCTGCTTCAC & \\
\hline \multirow[t]{2}{*}{ TBP1 } & \multirow[t]{2}{*}{ DQ845178.1 } & F: AACAGTTCAGTAGTTATGAGC & \multirow[t]{2}{*}{153} \\
\hline & & R: AGATGTTCTCAAACGCTTCG & \\
\hline \multirow[t]{2}{*}{ ACTB } & \multirow[t]{2}{*}{ XM_003124280.3 } & F: TGGCGCCCAGCACGATGAAG & \multirow[t]{2}{*}{149} \\
\hline & & R: GATGGAGGGGCCGGACTCGT & \\
\hline
\end{tabular}

Total RNA extraction, reverse transcription, and real-time PCR

Total RNA was extracted from the 11-tissue samples using Trizol (TaKaRa, China). The integrity, purity, and concentration of total RNA samples were determined using $2.2 \%$ formaldehyde denaturalization gel electrophoresis and UV spectrophotometry. Total RNA was stored at $-70^{\circ} \mathrm{C}$ prior to conversion to CDNA via reverse transcription.

The reverse transcription reaction mixture $(10 \mu \mathrm{L}$ total) consisted of $2 \mu \mathrm{L} 5 \mathrm{X}$ PrimerScript buffer reaction solution, $0.5 \mu \mathrm{L}$ PrimerScript RT enzyme mix I, $0.5 \mu \mathrm{L}$ oligo dT, $0.5 \mu \mathrm{L}$ random 6-mers, $500 \mathrm{ng}$ total RNA, and RNase-free $\mathrm{H}_{2} \mathrm{O}$. The reverse transcription conditions were set at $37^{\circ} \mathrm{C}$ for $15 \mathrm{~min}$ and $85^{\circ} \mathrm{C}$ for $5 \mathrm{~s}$. The resulting cDNA was stored at $4^{\circ} \mathrm{C}$.

cDNA was subsequently amplified using real-time PCR, and the real-time PCR mixture (20 $\mu \mathrm{L}$ total) consisted of $1 \mu \mathrm{L}$ template, $0.4 \mu \mathrm{L} 10 \mu \mathrm{M}$ primers (forward and reverse), $0.4 \mu \mathrm{L} 50 \mathrm{X}$ ROX Reference Dye II, $10 \mu \mathrm{L} 2 \mathrm{X}$ SYBR Green Real-Time PCR Master Mix, and $7.8 \mu \mathrm{L} \mathrm{ddH}_{2} \mathrm{O}$. The real-time PCR conditions were as follows: one cycle at $95^{\circ} \mathrm{C}$ for $30 \mathrm{~s} ; 40$ cycles at $95^{\circ} \mathrm{C}$ for 5 $\mathrm{s}$ and at $60^{\circ} \mathrm{C}$ for $34 \mathrm{~s}$; and a final step at $4^{\circ} \mathrm{C}$. The dissociation curve was analyzed following amplification, and a dissociation curve $\mathrm{Tm}$ of $85 \pm 0.8^{\circ} \mathrm{C}$ was used to determine the specificity of the amplification. Each sample was amplified three times, and the average was calculated.

\section{Statistical analysis}

The real-time PCR results were analyzed using the $2^{-\Delta \Delta C t}$ method, where $\Delta \Delta C t=$ (average $\mathrm{Ct}$ value of target genes in the test group - geometric mean value of $\mathrm{Ct}$ values of reference genes in the test group) - (average $\mathrm{Ct}$ value of target genes in the control group - geometric mean value of $\mathrm{Ct}$ values of reference genes in the control group). Statistical analyses were performed with the SPSS 15.0 software, and differences in FUT1 and FUT2 expression levels among the porcine breeds were analyzed using LSD multiple comparisons.

\section{RESULTS}

\section{Melting and amplification curves from real-time PCR analyses}

The real-time PCR results were analyzed with the Applied Biosystems Sequence detec- 
tion software (7500 Fast System SDS Software version 1.4). Both FUT1 and FUT2 exhibited a specific peak, and there were no primer dimers or non-specific products, which suggested that the amplification was specific. The FUT1 and FUT2 melting and amplification curves are shown in Figure S1.

\section{FUT1 and FUT2 expression levels in the 11 tissues of the three porcine breeds}

FUT1 and FUT2 were expressed in the 11 tissues of the three porcine breeds. Furthermore, the expression levels of the two genes were somewhat similar. The expression levels of both FUT1 and FUT2 were high in the liver, lungs, kidneys, stomach, duodenum, and jejunum, and they were low in the heart and muscle. FUT2 had medium expression levels in the spleen, thymus, and lymph nodes (Figures 1-3).

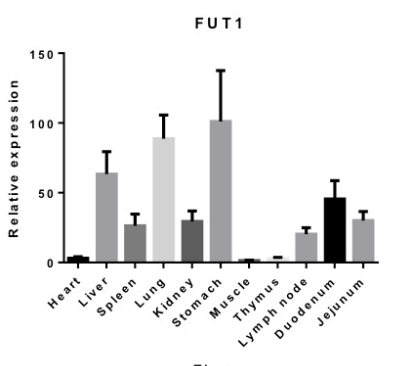

Tissu

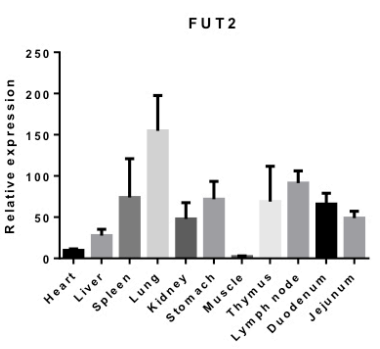

Tissue

Figure 1. Expression levels of FUT1 and FUT2 in 11 tissues of Large White pigs.
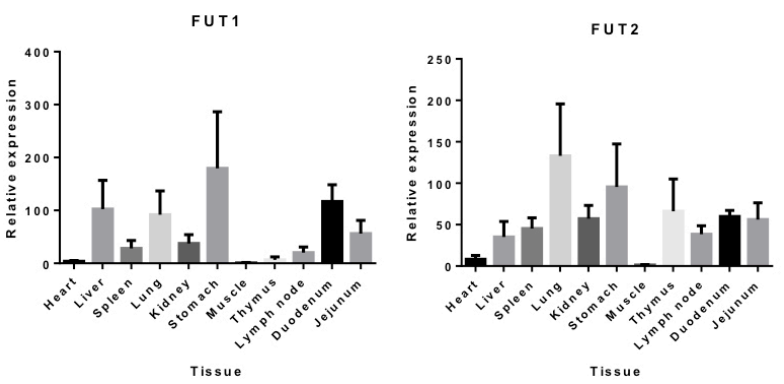

Figure 2. Expression levels of FUT1 and FUT2 in 11 tissues of Sutai pigs.
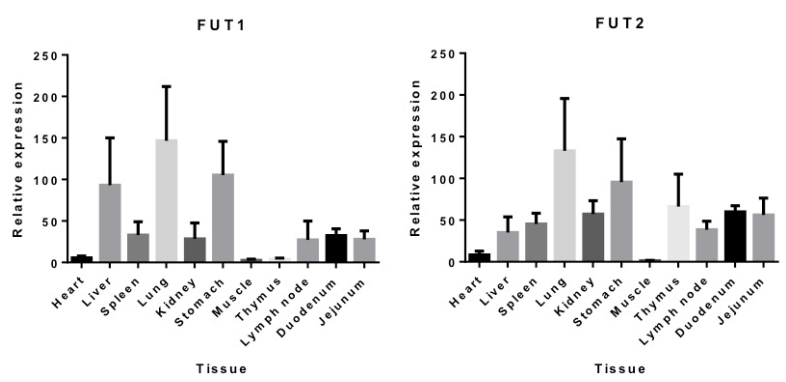

Figure 3. Expression levels of FUT1 and FUT2 in 11 tissues of Meishan pigs. 


\section{FUT1 and FUT2 expression levels in the duodenum and jejunum}

E. coli adheres to receptors expressed on the surface of intestinal cells. Therefore, in this experiment, we analyzed the expression levels of FUT1 and FUT2 in the duodenum and jejunum. Sutai pigs had higher FUT1 expression levels than Large White and Meishan pigs $(P<0.05)$. However, FUT2 expression levels were lower in Sutai pigs than in Large White and Meishan pigs $(P<$ 0.05). There were no significant differences in FUT1 and FUT2 expression levels between Large White and Meishan pigs ( $P>0.05$; Figures 4 and 5 ).

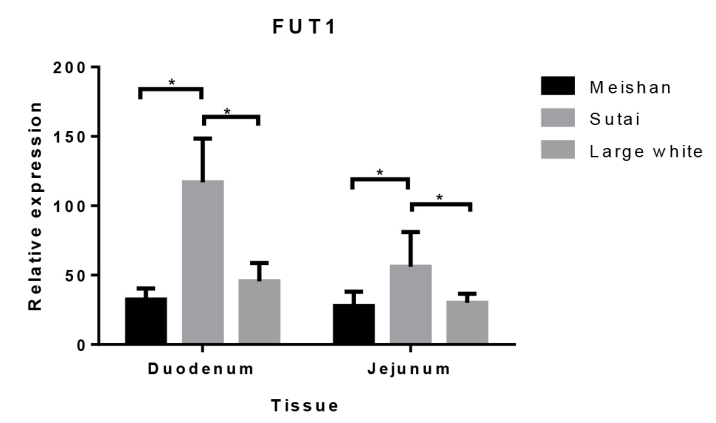

Figure 4. Differential expression analysis of FUT1 in duodenum and jejunum.

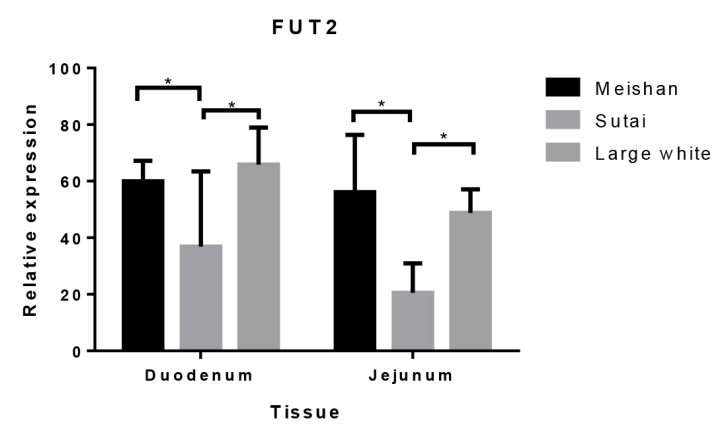

Figure 5. Differential expression analysis of FUT2 in duodenum and jejunum.

\section{DISCUSSION}

PWD in piglets is caused by enterotoxins produced by $E$. coli F18 bacteria after binding to receptors on the small intestinal brush border. Therefore, E. coli F18 pathogenicity is dependent on the presence of specific intestinal receptors (Bertin and Duchet-Suchaux, 1991; Berschinger et al., 1990, 1993). Coddens et al. (2007) reported that E. coli F18 receptor expression levels increased in Landrace pigs from 0 to 3 weeks of age, and they stabilized between 3 and 23 weeks of age. Unweaned piglets are not susceptible to $E$. coli because the milk antibodies confer protection against enteric infections (Deprez et al., 1986). In this study, the piglet specimens had been weaned for 1 week, and weaned piglets are very susceptible to $E$. coli F18 infections at this age (35 days old). The E. coli F18 receptor is a type $1 \mathrm{H}$ antigen of the ABO blood group and a glycosphingolipid derivative (Coddens et al., 2009). Studies reported that $A B H$ blood group antigens 
were primarily synthesized by the globo- and lactose-series of glycosphingolipid biosynthetic pathways (Hakomori, 2000). Moreover, $\mathrm{H}$ antigens were synthesized during the glycosphingolipid biosynthetic pathway, and neutral-, lactose-, and novel lactose-series glycosphingolipid biosynthetic pathways were utilized based on the glycosphingolipid biosynthesis-globo series pathway (Kannagi et al., 1983). Therefore, the glycosphingolipid biosynthesis-globoseries pathway plays an important role in the synthesis of the E. coli F18 receptor. According to the glycosphingolipid biosynthesis-globo-series pathway (Figure S2), FUT1 and FUT2 are involved in the synthesis of the intestinal receptor. In this study, 35-day-old Large White (foreign porcine breed), Meishan (domestic porcine breed), and Sutai pigs (with resistance to $E$. coli F18) were used, and FUT1 and FUT2 expression levels in 11 tissues of the three porcine breeds were analyzed using real-time PCR. Additionally, the correlation between FUT1 and FUT2 expression levels and resistance to $E$. coli F18 was calculated.

The expression profiles of the two genes of interest were similar among the breeds. Furthermore, the expression levels of FUT1 and FUT2 were higher in the liver, lungs, kidneys, stomach, duodenum, and jejunum than in other tissues. Saccharides are often the structural components of hormones, enzymes, cell surface receptors, the cell matrix, and connective tissue. Accordingly, FUT1 and FUT2 were expressed in the liver, lungs, kidneys, stomach, and intestinal tissue. It is noteworthy that FUT2 had medium expression levels in the spleen, thymus, and lymph nodes (i.e., organs where lymphocyte and the other immune cells differentiate).

Studies reported that FUT1 controls the adhesion of E. coli F18 (Imberechts et al., 1996; Meijerink et al., 1997, 2000). However, Coddens et al. (2009) observed that the E. coli F18 receptor is a type $1 \mathrm{H}$ antigen catalyzed by $\alpha 2$-fucosyltransferase that is encoded by FUT2 as opposed to a type $2 \mathrm{H}$ antigen catalyzed by $\alpha 1$-fucosyltransferase that is encoded by FUT1, and Moonens et al. (2012) and Lonardi et al. (2013) validated these results. Additionally, FUT1 glycosyltransferase converts type $1 \mathrm{H}$ precursors into type $1 \mathrm{H}$ blood group antigens (Kyprianou et al., 1990; Liu et al., 1998; Mathieu et al., 2004). FUT2 expression levels were significantly lower in E. coli F18-resistant piglets than those in E. coli 18-sensitive piglets, and Meijerink et al. (2000) reported that FUT2 expression levels were high in sensitive individuals and insignificant in resistant subjects. The high FUT2 expression levels contributed to high levels of fucosyltransferase in E. coli F18-sensitive piglets. In this study, FUT1 expression levels were significantly higher in Sutai pigs than in Large White and Meishan pigs $(P<0.05)$. On the other hand, FUT2 expression levels in Sutai pigs were significantly lower than those detected in Large White and Meishan pigs $(P<0.05)$. Epidemiological data revealed that morbidity rates associated with E. coli F18 infections did not differ significantly between the domestic and foreign breeds. Additionally, the results revealed that there were no significant differences in FUT1 and FUT2 expression levels between Large White and Meishan pigs $(P>0.05)$. Therefore, the high expression of FUT1 and the low expression of FUT2 in Sutai pigs with resistance to $E$. coli F18 affected the activity of FUT1 and FUT2 enzymes, respectively. Furthermore, the formation of type $1 \mathrm{H}$ antigens and type $2 \mathrm{H}$ antigens reduced the adhesion of $E$. coli F18. Low FUT2 expression levels contributed to E. coli F18 resistance in Sutai pigs. Therefore, further studies should evaluate the antagonistic relationship between FUT1 and FUT2 expression levels, and the relationship between FUT1, FUT2, and other genes in the glycosphingolipid biosynthetic pathway should also be examined.

\section{Conflicts of interest}

The authors declare no conflict of interest. 


\section{ACKNOWLEDGMENTS}

Research supported by the Natural Science Foundation of the Jiangsu Higher Education Institutions of China (\#14KJA230003), the National Natural Science Foundation of China (\#31472066, \#31372285), the Genetically Modified Organisms Technology Major Project (\#2014ZX0800601B), and the Priority Academic Program Development of Jiangsu Higher Education Institutions (PAPD).

\section{REFERENCES}

Bao WB, Wu SL, Musa HH, Zhu GQ, et al. (2008). Genetic variation at the alpha-1-fucosyltransferase (FUT1) gene in Asian wild boar and Chinese and Western commercial pig breeds. J. Anim. Breed. Genet. 125: 427-430. http://dx.doi.org/10.1111/ j.1439-0388.2008.00722.x

Bao WB, Ye L, Pan ZY, Zhu J, et al. (2012). Microarray analysis of differential gene expression in sensitive and resistant pig to Escherichia coli F18. Anim. Genet. 43: 525-534. http://dx.doi.org/10.1111/j.1365-2052.2011.02287.x

Bertin AM and Duchet-Suchaux MF (1991). Relationship between virulence and adherence of various enterotoxigenic Escherichia coli strains to isolated intestinal epithelial cells from Chinese Meishan and European large white pigs. Am. J. Vet. Res. 52: 45-49.

Bertschinger HU, Bachmann M, Mettler C, Pospischil A, et al. (1990). Adhesive fimbriae produced in vivo by Escherichia coli 0139:K12(B):H1 associated with enterotoxaemia in pigs. Vet. Microbiol. 25: 267-281. http://dx.doi.org/10.1016/03781135(90)90083-8

Bertschinger HU, Stamm M and Vögeli P (1993). Inheritance of resistance to oedema disease in the pig: experiments with an Escherichia coli strain expressing fimbriae 107. Vet. Microbiol. 35: 79-89. http://dx.doi.org/10.1016/0378-1135(93)90117-P

Boldin B (2008). Persistence and spread of gastro-intestinal infections: the case of enterotoxigenic Escherichia coli in piglets. Bull. Math. Biol. 70: 2077-2101. http://dx.doi.org/10.1007/s11538-008-9348-8

Coddens A, Verdonck F, Tiels P, Rasschaert K, et al. (2007). The age-dependent expression of the F18+ E. coli receptor on porcine gut epithelial cells is positively correlated with the presence of histo-blood group antigens. Vet. Microbiol. 122: 332-341. http://dx.doi.org/10.1016/j.vetmic.2007.02.007

Coddens A, Diswall M, Angström J, Breimer ME, et al. (2009). Recognition of blood group ABH type 1 determinants by the FedF adhesin of F18-fimbriated Escherichia coli. J. Biol. Chem. 284: 9713-9726. http://dx.doi.org/10.1074/jbc.M807866200

Deprez P, Van den Hende C, Muylle E and Oyaert W (1986). The influence of the administration of sow's milk on the postweaning excretion of hemolytic $E$. coli in the pig. Vet. Res. Commun. 10: 469-478. http://dx.doi.org/10.1007/BF02214010

HakomoriS(2000).Traveling fortheglycosphingolipid path. Glycoconj. J.17:627-647.http://dx.doi.org/10.1023/A:1011086929064

Imberechts H, Wild P, Charlier G, De Greve H, et al. (1996). Characterization of F18 fimbrial genes fedE and fedF involved in adhesion and length of enterotoxemic Escherichia coli strain 107/86. Microb. Pathog. 21: 183-192. http://dx.doi. org/10.1006/mpat.1996.0053

Kannagi R, Cochran NA, Ishigami F, Hakomori S, et al. (1983). Stage-specific embryonic antigens (SSEA-3 and -4) are epitopes of a unique globo-series ganglioside isolated from human teratocarcinoma cells. EMBO J. 2: 2355-2361.

Kyprianou P, Betteridge A, Donald AS and Watkins WM (1990). Purification of the blood group H gene associated alpha-2-Lfucosyltransferase from human plasma. Glycoconj. J. 7: 573-588. http://dx.doi.org/10.1007/BF01189078

Liu YH, Fujitani N, Koda $\mathrm{Y}$ and Kimura $\mathrm{H}$ (1998). Distribution of $\mathrm{H}$ type 1 and of $\mathrm{H}$ type 2 antigens of ABO blood group in different cells of human submandibular gland. J. Histochem. Cytochem. 46: 69-76. http://dx.doi.org/10.1177/002215549804600109

Lonardi E, Moonens K, Buts L, de Boer AR, et al. (2013). Structural sampling of glycan interaction profiles reveals mucosal receptors for fimbrial adhesins of enterotoxigenic Escherichia coli. Biology (Basel) 2: 894-917. http://dx.doi.org/10.3390/ biology2030894

Mathieu S, Prorok M, Benoliel AM, Uch R, et al. (2004). Transgene expression of alpha(1,2)-fucosyltransferase-I (FUT1) in tumor cells selectively inhibits sialyl-Lewis $\mathrm{x}$ expression and binding to E-selectin without affecting synthesis of sialylLewis a or binding to P-selectin. Am. J. Pathol. 164: 371-383. http://dx.doi.org/10.1016/S0002-9440(10)63127-6

Meijerink E, Fries R, Vögeli P, Masabanda J, et al. (1997). Two $\alpha(1,2)$ fucosyltransferase genes on porcine chromosome $6 q 11$ are closely linked to the blood group inhibitor (S) and Escherichia coli F18 receptor (ECF18R) loci. Mamm. Genome 8: 736-741. http://dx.doi.org/10.1007/s003359900556

Meijerink E, Neuenschwander S, Fries R, Dinter A, et al. (2000). A DNA polymorphism influencing $\alpha(1,2)$ fucosyltransferase activity of the pig FUT1 enzyme determines susceptibility of small intestinal epithelium to Escherichia coli F18 adhesion. Immunogenetics 52: 129-136. http://dx.doi.org/10.1007/s002510000263 
Moonens K, Bouckaert J, Coddens A, Tran T, et al. (2012). Structural insight in histo-blood group binding by the F18 fimbrial adhesin FedF. Mol. Microbiol. 86: 82-95. http://dx.doi.org/10.1111/j.1365-2958.2012.08174.x

Van den Broeck W, Cox E, Oudega B and Goddeeris BM (2000). The F4 fimbrial antigen of Escherichia coli and its receptors. Vet. Microbiol. 71: 223-244. http://dx.doi.org/10.1016/S0378-1135(99)00174-1

Vögeli P, Meijerink E, Fries R, Neuenschwander S, et al. (1997). [A molecular test for the detection of E. coli F18 receptors: a breakthrough in the struggle against edema disease and post-weaning diarrhea in swine]. Schweiz. Arch. Tierheilkd. 139: 479-484.

Wu SL, Yuan ZW, Ju HP, Huang XG, et al. (2007). Polymorphisms of the FUT1 gene M307 locus in post-weaning Sutai breed piglet and resistance to F18 fimbrial Escherichia coli in vitro. Chin. J. Prev. Vet. Med. 29: 783-787.

Yan XM, Ren J, Guo YM, Ding NS, et al. (2003). Research on the genetic variations of a1-fucosytransferase (FUT1) gene in 26 pig breeds. Yi Chuan Xue Bao 30: 830-834.

\section{Supplementary material}

Figure S1. FUT1 and FUT2 melting and amplification curves in different tissues.

Figure S2. Gene interaction network of seven glycosylation transferase enzymes in the STRING database.

http://www.geneticsmr.com/year2016/vol15-1/pdf/gmr7613 supplementary.pdf 